\title{
P-0420 Effect of saxagliptin, with and without acarbose, on postprandial glycaemia in Chinese patients with type 2 diabetes
}

\author{
Xuyi Wang ${ }^{1}$, Tongzhi Wu², Zilin Sun ${ }^{1}$
}

${ }^{1}$ Department of Endocrinology, Zhongda Hospital, and Institute of Diabetes, School of Medicine, Southeast University, Nanjing, China;
2 Discipline of Medicine, The University of Adelaide, Adelaide, Australia

Background and aim : Dipeptidyl peptidase-4 (DPP-4) inhibitors prevent rapid inactivation of the incretin hormone glucagon-like peptide-1 (GLP-1) to improve glycaemic control in type 2 diabetes. Malabsorption of carbohydrates induced by alpha glucosidase inhibitors (e.g. acarbose) has been shown to enhance postprandial GLP-1 secretion and, according, may potentiate the lowering of blood glucose by DPP-4 inhibitors. We evaluated the effects of the DPP-4 inhibitor, saxagliptin, with or without acarbose, on the glycaemic, intact GLP-1 and insulin responses to a high carbohydrate meal in Chinese patients with type 2 diabetes.

Method : 16 patients with diet-controlled type 2 diabetes (age $57.2 \pm 2.2$ years; 10 males; HbA1c $6.8 \pm 0.1 \%$; BMI $23.4 \pm$ $0.6 \mathrm{~kg} / \mathrm{m}^{2}$ ) were studied on 4 occasions, separated by at least 7 days each, in a randomised fashion. On each study day, patients consumed $30 \mathrm{~mL}$ water with $5 \mathrm{mg}$ saxaglipin or water only (at $\mathrm{t}=$ -60 min), followed 50 min later by a mashed potato meal (368.5 kcal; carbohydrate $61.4 \mathrm{~g}$; protein $7.4 \mathrm{~g}$; fat $8.9 \mathrm{~g}$ ) with or without $100 \mathrm{mg}$ acarbose in $10 \mathrm{~min}$ (during $\mathrm{t}=-50-0 \mathrm{~min}$ ). Accordingly, the four treatments were: (i) control + control (PLBO), (ii) control + acarbose (ACBO), (iii) saxagliptin + control (SAXA), and (iv) saxagliptin + acarbose (COMB). Arterialised venous blood was sampled at a regular interval during $t=-60-240 \mathrm{~min}$ for the measurements of plasma glucose, intact GLP-1 and insulin. Incremental areas under the curves (iAUCs) during $t=-60-240$ min for these measures were calculated, and compared using two-factor repeated measures ANOVA, with ACBO and SAXA as factors.

Results : SAXA reduced plasma glucose $(20.3 \pm 2.2$ $\mathrm{mmol} / \mathrm{L}^{*} \mathrm{~h}$ for SAXA and $15.8 \pm 2.1 \mathrm{mmol} / \mathrm{L}^{*} \mathrm{~h}$ for $\mathrm{COMB}$ vs. 25.1 $\pm 2.4 \mathrm{mmol} / \mathrm{L}^{*} \mathrm{~h}$ for $\mathrm{PLBO}$ and $18.0 \pm 2.1 \mathrm{mmol} / \mathrm{L}^{*} \mathrm{~h}$ for $\mathrm{ACBO}$, treatment effect: $P=0.009)$, increased plasma intact GLP-1 (58.2 $\pm 6.9 \mathrm{pmol} / \mathrm{L}^{*} \mathrm{~h}$ for SAXA and $63.1 \pm 7.7 \mathrm{pmol} / \mathrm{L}^{*} \mathrm{~h}$ for COMB vs. $22.4 \pm 5.7 \mathrm{pmol} / \mathrm{L}^{*} \mathrm{~h}$ for $\mathrm{PLBO}$ and $30.5 \pm 4.3 \mathrm{mmol} / \mathrm{L}^{*} \mathrm{~h}$ for $\mathrm{ACBO}$, $P<0.001$ ), without affecting plasma insulin.

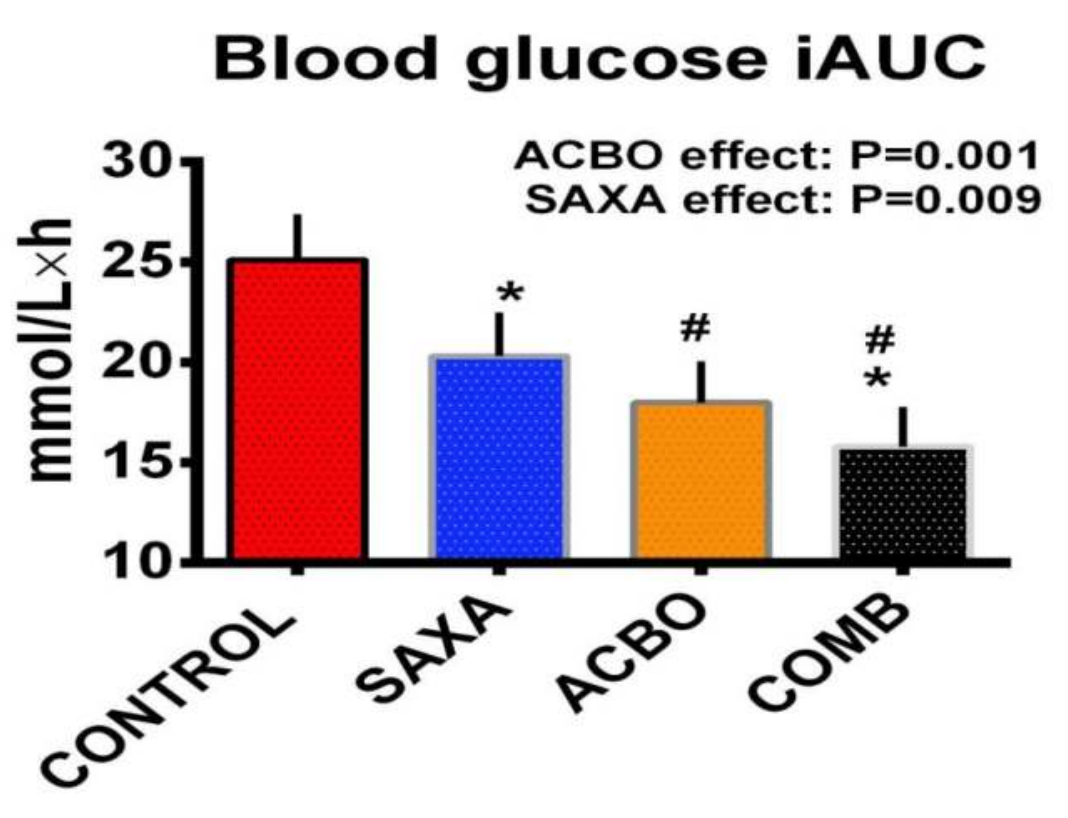

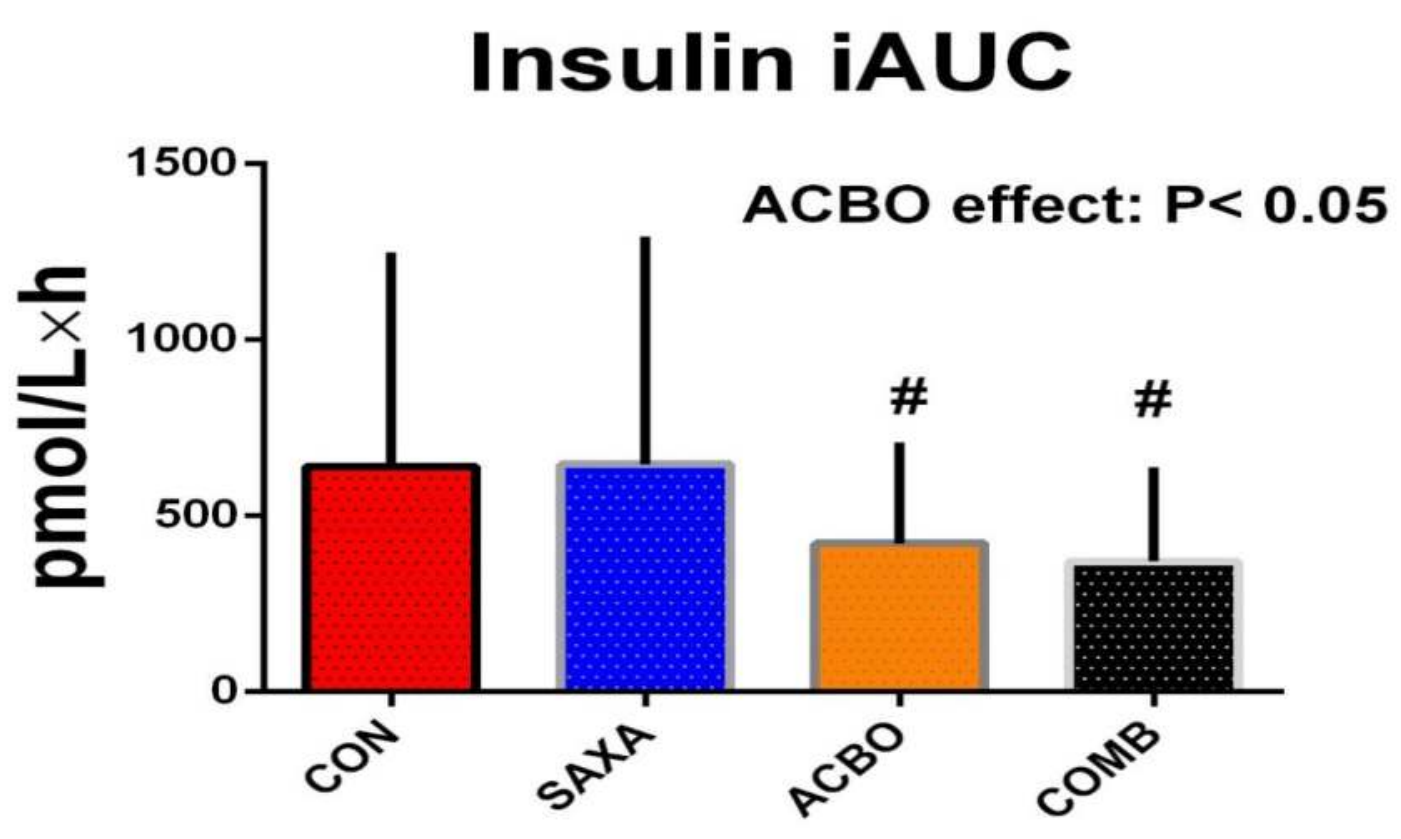

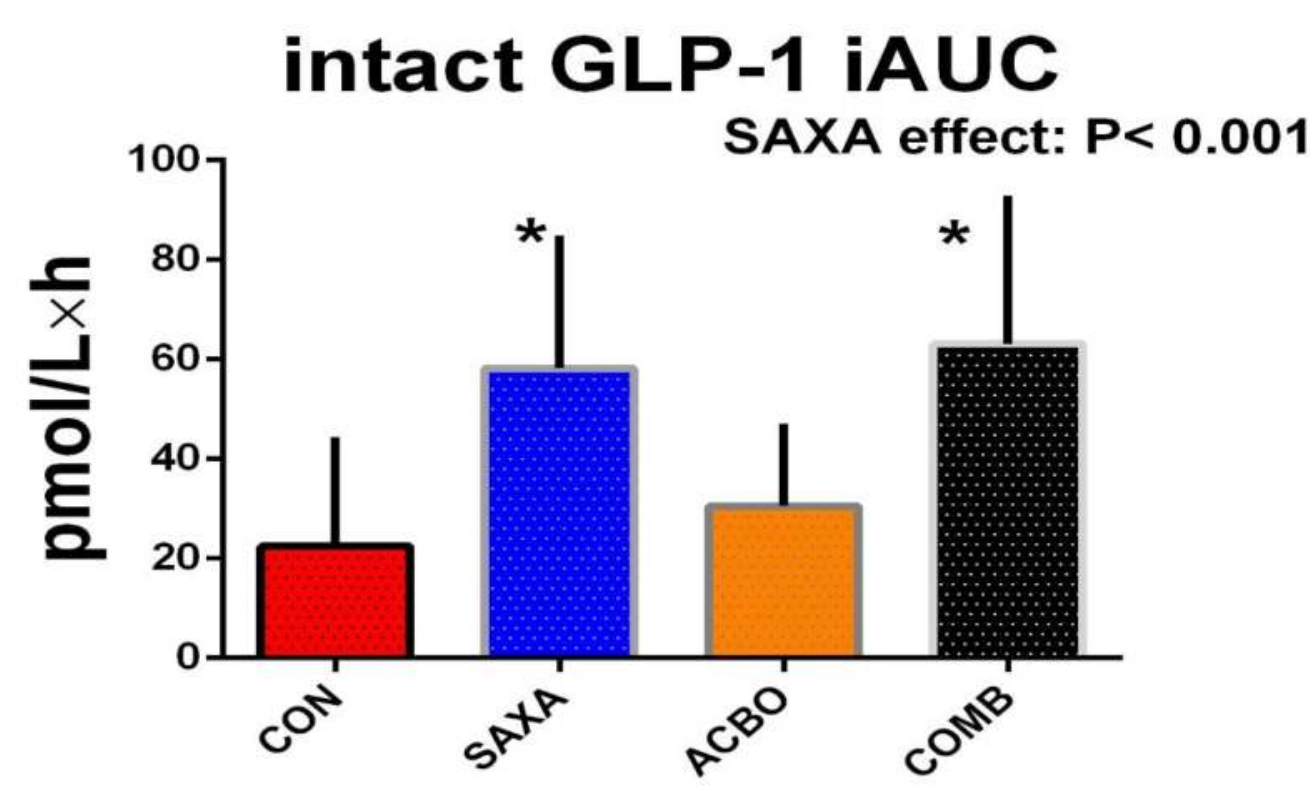

In contrast, ACBO was associated with lower plasma glucose $(P=$ $0.001)$ and insulin $(P<0.05)$, without any effect on plasma intact GLP-1. In the presence of ACBO, plasma glucose was lower $(P<$ 0.05), and plasma intact GLP-1 was higher $(P=0.001)$, with SAXA vs. control, without any difference in plasma insulin. In the presence of SAXA, both plasma glucose and insulin were lower $(P$ $<0.05$ for both) with ACBO vs. control, without any difference in plasma intact GLP-1.

Discussion : In diet-controlled Chinese patients with type 2 diabetes, saxagliptin diminished postprandial glycaemic excursion, associated with increased plasma intact GLP-1, without affecting insulin, whereas acarbose reduced both plasma glucose and insulin, probably due to inhibition of carbohydrate digestion and absorption, without affecting plasma intact GLP-1. Nevertheless, the combination of saxagliptin with acarbose reduced postprandial glycaemic excursion more effectively than either alone, supporting the use of DPP-4 inhibitors with acarbose for the management of postprandial hyperglycaemia in Chinese patients with type 2 diabetes. 